\title{
MANAJEMEN REKAYASA LALU LINTAS PENGEMBANGAN WISATA KAMPUNG COKLAT
}

\author{
Edi Hardi Sunyoto ${ }^{* 1}$, Ahmad Ridwan ${ }^{2}$, Sigit Winarto ${ }^{3}$. \\ 1,2,3 Fakultas Teknik, Universitas Kadiri. \\ e-mail:*1edihardi@gmail.com,2ahmad_ridwan@unik-kediri.ac.id, \\ 3sigit.winarto@unik-kediri.ac.id.
}

\begin{abstract}
Responding to the development of the brown village tourist area in Golodok Blorok Kademnagan Blitar, it will cause seizures that have an impact on decreasing the performance of roads and intersections around the area, and cause a high level of accidents. can minimize the decline in the performance of roads and intersections and reduce or minimize the occurrence of accidents of visitors to the brown village area, and can provide solutions to traffic problems that occur due to the development of brown village tourism. The method used in this research is based on the Indonesian Road Capacity Manual (MKJI 1997) and other related regulations. This reliable step begins with conducting a traffic survey in the area that has been determined and asks for data on the number of visitors and the number of vehicles parked for 1 year to the manager of the Brown Village tourist area which then estimates the trip generation and sets the andalalin classification. After that, analyze the traffic performance on existing conditions and analyze the conditions of traffic management without and with regional development, as well as develop alternative improvements to the impact of traffic due to the development of the brown village tourist area.
\end{abstract}

Keywords: $\quad$ Brown Village, Tourism, Traffic Management, Traffic Impact

\begin{abstract}
Abstrak
Menyikapi berkembangnya kawasan wisata kampung coklat di jl Golodok Blorok Kademnagan Blitar , akan menimbulkan bangkitan yang berdampak pada penurunan kinerja ruas jalan dan simpang di sekitar kawasan tersebut, serta menimbulkan tingkat kecelakaan yang tinggi, Untuk itu perlu di lakukan Analisis Dampak Lalu Lintas (Andalalin) agar dapat meminimalisir penurunan kinerja ruas jalan dan simpangdanmengurangiatauminimalisirterjadinyakecelakaanpengunjungkawasan kampong coklat, serta dapat memberikan solusi pemecahan masalah lalu lintas yang terjadi akibat pengembangan wisata kampung coklat. Metode yang digunakan pada penelitia ini didasarkan pada Manual Kapasitas Jalan Indonesia (MKJI 1997) dan peraturan terkait lainya.Tahapan andalalin ini diawali dengan melakukan survei lalu lintas di area yang sudah di tentukan dan meminta data jumlah pengunjung serta jumlah kendaraan yang parkir selama 1 tahun kepada pengelola Kawasan wisata kampong coklat yang selanjutnya memperkirakan bangkitan perjalanan dan menetapkan klasifikasi andalalin. Setelah itu , menganalisa kinerja lalu lintas pada kondisi eksisting dan menganalisa pada kondisi manajemen lalu lintas tanpa dan dengan pengembangan kawasan, serta menyusun alternatif perbaikan terhadap dampak lalu lintas akibat pengembangan kawasan wisata kampung coklat tersebut.
\end{abstract}

Kata Kunci : $\quad$ Kampung coklat, wisatawan, managemen lalu lintas, Dampak Lalu Lintas 


\section{PENDAHULUAN}

Pembangunan dan pengembangan kawasan kampung coklat mempunyai pengaruh terhadap lalu lintas di sekitarnya [1][2][3]. Analisis dampak lalu lintas dipergunakan untuk memprediksi apakah infrastruktur transportasi dalam daerah pengaruh pembangunan tersebut dapat melayani lalu lintas yang ada (eksisting) ditambah dengan lalu lintas yang dibangkitkan atau ditarik oleh perkembangan wilayah tersebut, [4][5][6]. Jika prasarana yang ada tidak dapat mendukung lalu lintas tersebut maka harus dilakukan kajian penanganan prasarana tersebut atau pengaturan manajemen terhadap lalu lintasnya, [7][8][9]. Pengembangan area wisata Kampung Coklat oleh Koperasi Serba Usaha Guyub Santoso terletak di Jalan Banteng Blorok RT01/RW06, Kademangan Blitar. Dengan pola kebijaksanaan pembangunan yang diterapkan, secara fisik Kampung Coklat dapat dianggap sebagai fasilitas hunian dalam suatu kota, [10][11]. Nilai yang terkandung dari adanya Kampung Coklat sebagai kawasan wisata yang sangat potensial, [12][13]. Menyikapi dampak dari rencana pengembangan Kampung Coklat, dimana kegiatan tersebut sebagai lokasi kawasan wisata unggulan dari Kabupaten Blitar yang berpotensi menimbulkan dampak terhadap penurunan kinerja jaringan jalan dikawasan sekitarnya, [14][15]. Hal ini diakibatkan karena kawasan wisata Kampung Coklat akan menimbulkan bangkitan dan tarikan perjalanan kedaerah tersebut. Oleh karena itu kawasan tersebut memiliki potensi penambah jumlah perjalanan yang secara hipotesis cukup signifikan, [16][17][18].

Rumusan masalah yang dapat diambil dalam pekerjaan ini adalah sebagai berikut : Bagaimana kondisi kinerja ruas jalan dan simpang akibat munculnya kegiatan dari Kawasan wisata kampung coklat ? Bagaimana antisipasi manajemen rekayasa lalu lintas yang sesuai dengan kondisi wisata kampung coklat?

Serta maksud dari studi ini adalah mengetahui sejauh mana dampak Kampung Coklat terhadap lalu lintas disekitar lokasi. Sedangkan tujuannya dari studi ini adalah sebagai berikut: Melakukan penilaian kinerja ruas jalan dan simpang di sekitar area wisata Kampung Coklat ( area terdampak / keep ment area ), memberikan saran atau masukan rencana antisipasi pengaturan arus kendaraan dan pengunjung dengan Manajemen Rekayasa lalu lintas kawasan wisata Kampung Coklat Dalam Undang-Undang Nomor22 Tahun 2009 Tentang Lalu Lintas Angkutan Jalan, manajemen dan rekayasa lalu lintas merupakan serangkaian usaha dan kegiatan yang meliputi perencanaan, pengadaan, pemasangan, pengaturan, dan pemeliharaan fasilitas 25 perlengkapan jalan dalam rangka mewujudkan, mendukung dan memelihara keamanan, keselamatan, ketertiban, dan kelancaran lalu lintas. Seperti yang diamanatkan dalam Undang-Undang Nomor 22 Tahun 2009 tentang Lalu Lintas dan Angkutan Jalan tersebut di atas, manajemen dan rekayasa lalu lintas dilaksanakan untuk mengoptimalkan penggunaan jaringan jalan dan gerakan lalu lintas, 
[19]. Pada dasarnya manajemen dan rekayasa lalu lintas meliputi kegiatan perencanaan, pengaturan, perekayasaan, pemberdayaan, dan pengawasan.

\section{METODE PENELITIAN}

Untuk mengetahui dan mempermudah studi, maka perlu dibuat bagan alir studi. Bagan alir studi dapat dilihat sebagai berikut;

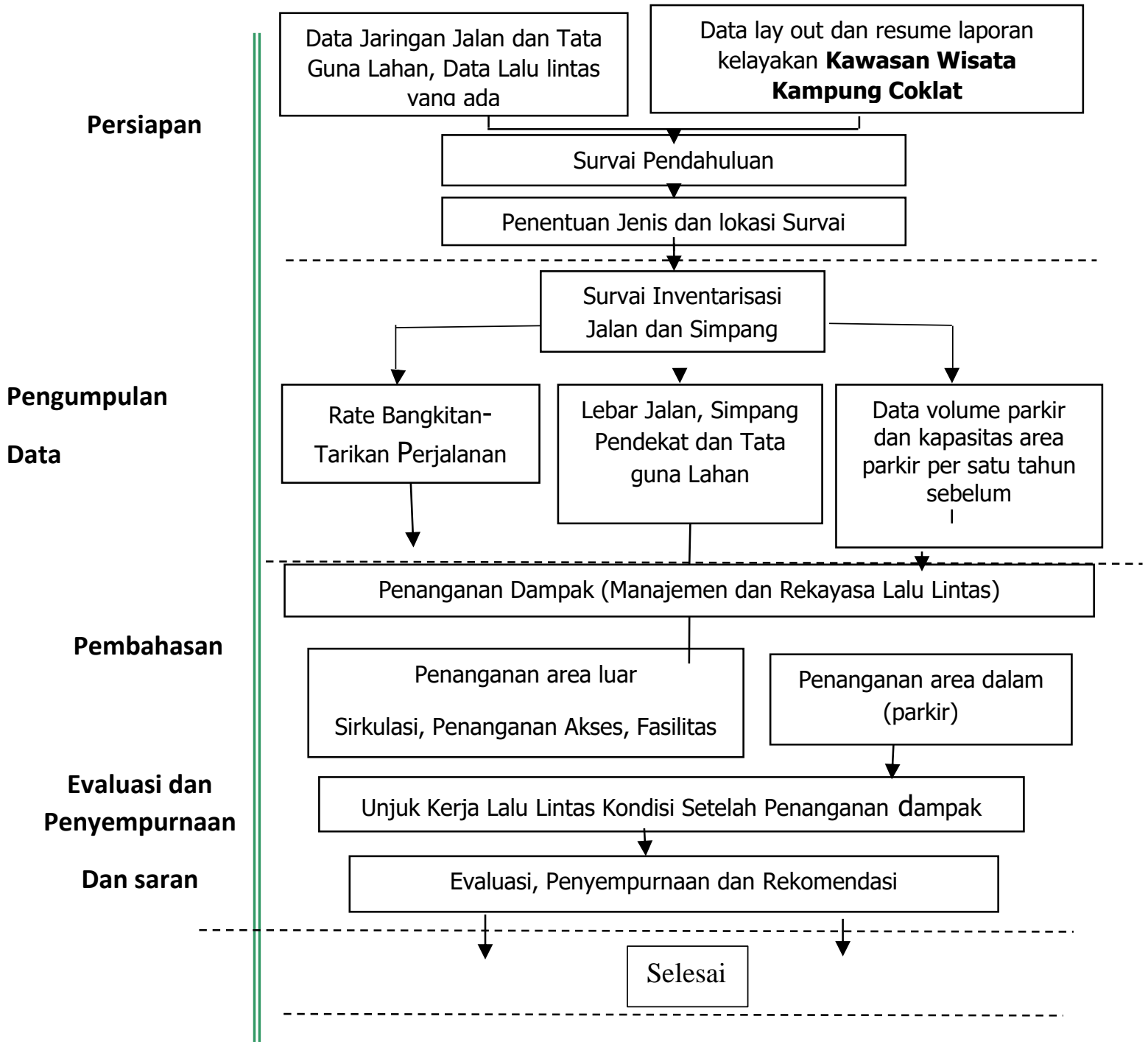

\subsection{Alur Penelitian}

Kelengapan administrasi dan perizinan merupakan sebuah usaha awal yang dilakuan dalam menjalin suatu bentuk kerja sama dan koordinasi dengan pihak lain guna memperlancar proses penyelesaian penelitian berkaordinasi dengan pengelola kawasan kampong coklat Blitar. Sebelum pengumpul data primer melakukan survei langsung di lapangan, terlebih dahulu wajib dilakukan survei pendahuluan guna mengidentifikasi kondisi umum secara teknis dan non teknis disekitar area studi. Dalam proses perencanaan transportasi, menetukan ruang lingkup wilayah studi 
berkaitan dengan dampak yang dapat ditimbulkan dari pembangunan suatu pusat aktivitas orang yang akan dikaji. Penentuan darah studi dilakukan dengan menggunaan peta jaringan jalan dan tata guna lahan yang didapat memudahkan untuk menentukan batas-batas wilayah yang akan dikaji yang kemudian dibagi tiap zona. Zona merupakan suatu daerah yang memiliki karak teristik yang sama untuk menyatakan asal dan tujuan perjalanan. Penetapan zona lalu lintas berfungsi untuk mengidentifikasi pola perjalanan berdasarkan asal dan tujuan perjalanan, [20][21]. Pola perjalanan merupakan representatif dari karakteristik perjalanan dalam suatu wilayah studi. Dalam rangka memudahkan mendapatkan data sekunder dari berbagai instansi terkait, seperti Bappeda, Dinas Perhubungan, Badan Pusat Statistik, pihak manajemen pengembang, metodologi komprehensif yang disusun oleh kami dimulai dengan tahap pengumpulan data, dalam hal ini data sekunder, [22][23]. Data-data yang dikumpulkan dalam tahap ini berupa identifikasi terhadap 2 (dua) masalah pokok yaitu :

1. Data jaringan jalan dan tataguna lahan di sekitar Area pembangunan. Dengan melakukan kegiatan survai di antaranya jumlah traffic dan kecepatan kendaraan yang melintas di depankwasan kampong coklat

2. Data rancang bangun (master plan).didapat dari pengembang wisata kampong coklat

\section{HASIL DAN PEMBAHASAN}

Dari hasil survai di dapatlah data data yang selanjutkan dari data tersebut di olah menjadi angka sebagai penetu model manajemen rekayasa lalu lintas di antaranya sebagai berikut :

Tabel 1. Pengunjung Kampung Coklat Desember 2018

\begin{tabular}{|c|c|c|c|}
\hline \multirow{2}{*}{ Waktu } & \multicolumn{2}{|c|}{ Kegiatan } & \multirow{2}{*}{ Keterangan } \\
\cline { 2 - 4 } & Observasi & Edukasi & \\
\hline Kerja (senin - sabtu) & 69207 & 4101 & 22 hari kegiatan edukasi \\
\hline Libur (akhir pekan) & 26907 & 321 & 3 hari kegiatan edukasi \\
\hline Libur (Hari besar \& nasional) & 8988 & 30 & 1 hari \\
\hline Total & 105102 & 4452 & 31 hari \\
\hline Rata - Rata & 3390 & 178 & \\
\hline
\end{tabular}

Sumber :Pengembang Kampung Coklat 
Tabel 2. Pengunjung Kampung Coklat Januari 2018

\begin{tabular}{|l|l|l|l|}
\hline \multirow{2}{*}{ Waktu } & \multicolumn{2}{|l|}{ Kegiatan } & \multirow{2}{*}{ Keterangan } \\
\cline { 2 - 4 } & Observasi & Edukasi & \\
\hline Kerja (senin - sabtu) & 36639 & 3544 & 22 hari kegiatan edukasi \\
\hline Libur (akhir pekan) & 37897 & 19 & 1 hari kegiatan edukasi \\
\hline Libur (Hari besar \& nasional) & 16464 & 0 & 1 hari \\
\hline Total & 91000 & 3563 & 31 hari \\
\hline Rata - Rata & 2935 & 155 & \\
\hline
\end{tabular}

Sumber :Pengembang Kampung Coklat

Tabel 3. Tingkat penggunaan ruang parkir

\begin{tabular}{|l|l|l|l|}
\hline \multicolumn{3}{|l|}{ Turn Over (tingkat penggunaan ruang parkir) } \\
\hline $\begin{array}{l}\text { Sepeda } \\
\text { Montor }\end{array}$ & 1.26 & kend/jam/SRP & \\
\hline Mobil & 2.06 & kend/jam/SRP & \\
\hline Elf & 0.10 & Kend/jam/SRP & \\
\hline Bus & 0.43 & kend/jam/SRP & \\
\hline Keterangan & $1.26>1$ & kend/jam/SRP & tidak memenuhi \\
\hline $\begin{array}{l}\text { Sepeda } \\
\text { Montor }\end{array}$ & $2.06>1$ & kend/jam/SRP & tidak memenuhi \\
\hline Mobil & $0.10<1$ & kend/jam/SRP & memenuhi \\
\hline Elf & $0.43>1$ & kend/jam/SRP & memenuhi \\
\hline Bus & & &
\end{tabular}

Sumber :Hasil Analsis 
Tabel 4.1 Rekap Hasil Survai Bangkitan/Tarikan

\begin{tabular}{|c|c|c|c|c|}
\hline \multirow{3}{*}{ Jam } & \multicolumn{4}{|c|}{ Kendaraan } \\
\hline & \multicolumn{2}{|l|}{ Keluar } & \multicolumn{2}{|l|}{ Masuk } \\
\hline & Mobil & Montor & Mobil & Montor \\
\hline $08.00-09.00$ & 10 & 21 & 14 & 27 \\
\hline $09.00-10.00$ & 8 & 16 & 5 & 21 \\
\hline $10.00-11.00$ & 14 & 15 & 16 & 25 \\
\hline $11.00-12.00$ & 19 & 33 & 26 & 31 \\
\hline $12.00-13.00$ & 4 & 26 & 17 & 14 \\
\hline $13.00-14.00$ & 4 & 29 & 15 & 19 \\
\hline $14.00-15.00$ & 10 & 13 & 20 & 24 \\
\hline $15.00-16.00$ & 7 & 13 & 12 & 19 \\
\hline $16.00-17.00$ & 6 & 13 & 9 & 26 \\
\hline $17.00-18.00$ & 2 & 15 & 2 & 20 \\
\hline $18.00-19.00$ & 7 & 16 & 3 & 22 \\
\hline $19.00-20.00$ & 10 & 17 & 14 & 28 \\
\hline $20.00-21.00$ & 6 & 18 & 11 & 17 \\
\hline $21.00-22.00$ & 3 & 17 & 11 & 15 \\
\hline $22.00-23.00$ & 3 & 18 & 7 & 11 \\
\hline
\end{tabular}

Sumber : Hasil survai

Dari hasil survai diatas maka dihasilkan tarikan / bangkitan tertinggi terjadi pada jam sibuk pagi yaitu pada jam 06.45 - 07.45 sebesar 19 mobil ( 29 smp/jam) dan 33 motor (49,2 smp/jam) untuk bangkitan serta 26 mobil (76 smp/jam) dan 31 motor (160,4 smp/jam) untuk tarikan. Dari hasil kajian dan survai dengan kegiatan diantranya pengukuran ruas jalan ,menghitung kecepatan kedaraan, jumlah kendaraan yang melitas dan masuk ke area kawasan kampong coklat, serta 
mendapatkan data jumla pengunjung serta jumlah kendaraan yang parkir. Dengan mengetahui kinerja lalu lintas pada masing - masing kondisi untuk yang akan datang, dapat dilihat besarnya dampak yang diakibatkan oleh pengembangan Kampung Coklat. Untuk mengantisipasi dampak yang terjadi berdasarkan dengan beberapa pertimbangan yang telah dijelaskan diatas maka dapat diusulkan penanganan secara detail (teknis) yaitu dengan melakukan antisipasi terhadap kendaraan - 30 kendaraan yang akan berhenti pada ruas jalan di sekitar akses keluar dan masuk dari Kampung Coklat sehingga dapat meningkatkan kapasitas pada ruas jalan. antisipasi yang dapt dilakukan adalah dengan melakukan hal - hal sebagai berikut :

1. Menyiapkan dan memfasilitasi pengunjung penjalan kaki / yang menyebrang jalan

2. Memasang rambu - rambu lalu lintas untuk mengatur aktifitas di area wisata

3. Memperluas area parking

4. Adanya petugas di persimpangan jalan guna membantu mengatur dan memudahkan kedaraan yang dating masuk maupun yang keluar.

\section{KESIMPULAN}

Rencana Pengembangan kawasan wisata kampong coklat Blitar akan mengakibatkan bangkitan kendaraan yang mana perlu adanya penambahan area parkir dan pengaturan akses parkir keluar masuk kendaraan pengunjung wisata kampong coklat. Serta adanya pemasangan rambu rambu di titik yang sudah di tentukan guna memperlancar aktifitas lalu lintas di area wisata kampong coklat. Berdasarkan hasil analisis yang telah dilakukan diperoleh kesimpulan sebagai berikut

1. Kinerja ruas Jalan banteng blorok (T-B) pada kondisi eksisting (Tahun2018) v/c ratio sebesar 0,51, JalanTritura (B-T) v / cratio sebesar 0,42 dengan tingkat pelayanan ruas jalan adalah "C" dan " Terjadi peningkatan pada tahun rencana dengan pembangunan 2024 pada ruas jalan Banteng Blorok (T-B) v/c sebesar 0,84 dengan tingkat pelayanan "E” dan pada ruas Jalan Tritura (T-B) v/c sebesar 0.83 dengan tingkat pelayanan "D", kondisi ini dapat menurunkan kecepatan dan membatasi pengemudi dalam berkendara diruas jalan.

2. Setelah adanya rekayasa penambahan kapasitas dengan melakukan pelebaran ruas jalan Banteng Blorok (T-B) menjadi 3 meter dan penambahan marka jalan dan penataan area parkir maka kinerja ruas Jalan $\mathrm{v} / \mathrm{c}$ ratio turun 0,56 menjadi dengan tingkat pelayanan " $\mathrm{C}$ " sehingga arus lalu lintas diharapkan menjadi lancar . 


\section{SARAN}

Untuk mengatasi dampak lalu lintas yang ada di kampung coklat dilakukan manajemen lalu lintas dengan pengaturan titik konflik, pengaturan akses keluar masuk kendaraan di area parkir dengan perambuan dan pengaturan parkir. Penanganan dampak lalu lintas dapat di lakukan dengan pengaturan sirkulasi lalu lintas orang maupun kendaraan dengan penempatan fasilitas dan di sediakan alat bantu Rambu sebagai pengatur aktifitas lalu lintas di area wisata kampung coklat

\section{UCAPAN TERIMAKASIH}

Dalam penyusunan artikel ini, penulis ucapkan terimakasih kepada dosen pembimbing dan Universitas Kadiri. Penulis berharap agar artikel ini dapat bermanfaat bagi pembaca.

\section{DAFTAR PUSTAKA}

[1] A. D. Limantara, A. I. Candra, and S. W. Mudjanarko, "Manajemen Data Lalu Lintas Kendaraan Berbasis Sistem Internet Cerdas Ujicoba Implementasi Di Laboratorium Universitas Kadiri,” 2017.

[2] F. Agyapong and T. K. Ojo, "Managing traffic congestion in the Accra Central Market, Ghana," J. Urban Manag., vol. 7, no. 2, pp. 85-96, 2018, doi: 10.1016/j.jum.2018.04.002.

[3] A. Theofilatos, G. Yannis, E. I. Vlahogianni, and J. C. Golias, "Modeling the effect of traffic regimes on safety of urban arterials: The case study of Athens," J. Traffic Transp. Eng. (English Ed., vol. 4, no. 3, pp. 240-251, 2017, doi: 10.1016/j.jtte.2017.05.003.

[4] F. A. Lestari and Y. Apriyani, "ANALISIS DAMPAK LALU LINTAS AKIBAT ADANYA PUSAT PERBELANJAAN DIKAWASAN PASAR PAGI PANGKALPINANG TERHADAP KINERJA RUAS JALAN,” J. Fropil, vol. 2, no. 1, pp. 32-44, 2014.

[5] W. I. Dharmawan, "Kajian Putar Balik (U-Turn) Terhdap Kemacetan," vol. 7, no. KoNTekS 7, pp. 189-196, 2013.

[6] Departeman Pekerjaan Umum Direktorat Jenderal Bina Marga, "Geometri Jalan Bebas Hambatan Untuk Jalan Tol," Standar Geom. Jalan Bebas Hambatan Untuk Jalan Tol, no. 010, 2009.

[7] R. Yuwono, Y. C. Sp, and L. D. K, "STUDY ANALISA VOLUME KENDARAAN PADA SIMPANG BERSINYAL DI PEREMPATAN ALUN ALUN KOTA KEDIRI,” Jurmateks, vol. 1, no. 1, pp. 101-111, 2018.

[8] F. D. Hobbs, Perencanaan dan Teknik lalu Lintas. Jogjakarta: Fakultas Teknik Universitas Gajah Mada, 1995. 
[9] A. I. Candra et al., "PENGECEKAN KELAYAKAN BANGUNAN GEDUNG SMA NEGERI 1 KOTA KEDIRI YANG DIGUNAKAN UNTUK AKTIFITAS,” Ukarst $J$. Univ. Kadiri Ris. Tek. Sipil, vol. 2, no. 2, pp. 108-116, 2019.

[10] W. T. Cahyono, Y. C. SP, and S. Winarto, "STUDI EFISIENSI PEMBERIAN AIR IRIGASI PADA DESA GROMPOL, KECAMATAN GAMPENGREJO, KABUPATEN KEDIRI,” Jurmateks, vol. 1, no. 1, pp. 12-21, 2018.

[11] R. Hidayah, A. Ridwan, and Y. C. S. P, "ANALISA PERBANDINGAN MANAJEMEN WAKTU ANTARA PERENCANAAN DAN PELAKSANAAN,”Jurmateks, vol. 1, no. 2, pp. 281-290, 2018.

[12] [Kementerian PUPR]. Kementerian Pekerjaan Umum dan Perumahan Rakyat, "Perencanaan Perkerasan Jalan Beton Semen," p. 52, 2003.

[13] B. Haryadi, "KEPADATAN KOTA DALAM PERSPEKTIF PEMBANGUNAN ( TRANSPORTASI ) BERKELANJUTAN,” pp. 87-96.

[14] R. Pramanasari, N. Qomariyah, D. Purwanto, and E. Yilipriyo, "PENERAPAN MANAJEMEN LALU LINTAS SATU ARAH PADA RUAS JALAN SULTAN AGUNG - SISINGAMANGARAJA - DR.WAHIDIN KOTA SEMARANG UNTUK PEMERATAAN SEBARAN BEBAN LALU LINTAS,” J. KARYA Tek. SIPIL, vol. 3, no. 1, pp. 142-153, 2014.

[15] A. Munawar, Manajemen Lalu Lintas Perkotaan. Jogjakarta: Beta Offset, 2004.

[16] N. Hidayah, "Disiplin Lalu Lintas Pengendara Sepeda Motor Roda Dua di Kecamatan Tampan Pekanbaru," J. FISIP, vol. 2, no. 1, pp. 1-15, 2015.

[17] A. Nashirudin, S. Winarto, and Sudjati, "PERENCANAAN CHECKDAM KALI NGASINAN KANAN DESA NOTOREJO KECAMATAN GONDANG KABUPATEN TULUNGAGUNG," Jurmateks, vol. 1, no. 2, pp. 192-203, 2018.

[18] A. I. Candra, "ANALISIS DAYA DUKUNG PONDASI STROUS PILE PADA PEMBANGUNAN GEDUNG MINI HOSPITAL UNIVERSITAS KADIRI,” Ukarst, vol. 1, no. 1, pp. 63-70, 2017.

[19] S. Awiyaningsih, H. Moetriono, and S. W. Mudjanarko, "ANALISIS DAMPAK LALU LINTAS PEMBANGUNAN MALL LAGOON AVENUE SUNGKONO TERHADAP KINERJA SIMPANG DI JALAN MAYJEND SUNGKONO - HR MUHAMMAD SURABAYA,” Tek. Eng. Sains J., vol. 2, no. 2, pp. 131-134, 2018.

[20] S. J. Legowo and D. Anggoro, "Studi Evaluasi Dampak Lalu Lintas Akibat Pembangunan Stasiun Pengisian Bahan Bakar Umum ( Spbu ) Manahan,”pp. 601-609, 2014.

[21] Direktorat Jendral Bina Marga, "Perencanaan Geometrik Jalan," Departemen Pekerjaan Umum. 2017. 
[22] J. Vironika, I. Bagus, M. Astawa, and I. P. A. Citra, "ANALISIS TINGKAT KEPADATAN LALU LINTAS DI KECAMATAN DENPASAR BARAT," pp. 1-11, 1983.

[23] R. G. Yahya, "Studi Permodelan Bangkitan Perjalanan di Perkotaan,” J. Tek. Sipil, vol. 3, no. 1, pp. 92-100, 2019, doi: 10.28932/jts.v3i1.1274. 